\title{
Synthesis and Characterization of Hybrid Fiber Scaffold for Medical Implants
}

\author{
Abere DV ${ }^{1 *}$, Ojo SA ${ }^{2}$, Akinwole $\mathrm{IE}^{3}$, Joseph $\mathrm{OD}^{1}$, Uzuh FD ${ }^{1}$, Adeosun $\mathrm{BS}^{3}$, Awe $\mathrm{A}^{3}$ and Ohwoekevwo \\ $\mathrm{JU}^{1}$
}

${ }^{1}$ National Metallurgical Development Centre, Nigeria

${ }^{2}$ Department of Mechanical Engineering, University of Akron, USA

${ }^{3}$ Department of Materials Science and Engineering, Obafemi Awolowo University, Nigeria

*Corresponding author: Abere DV, National Metallurgical Development Centre, Jos, Nigeria

To Cite This Article: Abere DV, Synthesis and Characterization of Hybrid Fiber Scaffold for Medical Implants. Am J Biomed Sci \& Res. 2020 - 6(6). AJBSR.MS.ID.001099. DOI: 10.34297/AJBSR.2020.06.001099.

Received: November 04, 2019; Published: 眥 January 16, 2020

\begin{abstract}
This work synthesized and characterized chitosan-silica based hybrid fiber from cowry shell and rice husk respectively with the aim of studying the behavior of a hybrid polymer-silicate composite via the electrospinning technique to produce nanofibers from natural polymer and agro waste, from which scaffolds can be produced which can be used for culturing and wound healing application in the biomedical field. The samples obtained were subjected to the following analyses: Energy Dispersive X-ray Florescent (ED-XRF), Fourier Transform Infrared Spectroscopy (FTIR), X-Ray Diffraction (XRD), Scanning Electron Microscopy (SEM) and Thermogravimetic Analysis (TA).

It was observed from the ED-XRF analysis that the major constituent of rice husk ash is silica (SiO2) with some associate metallic oxides. The peaks obtained from the FTIR analysis of the polymer confirm the characteristics features for the polysaccharide structure of chitosan while the characteristic and positions of the peaks observed in the extracted silica spectra showed similar position with that of the commercially available silica obtained from BDH chemicals UK. The Chitosan-silica hybrid has Si AOH and Si AO ASi with the respective bands within the regions of 3270$3400 \mathrm{~cm}-1$ and $989-1300 \mathrm{~cm}-1$.The X-ray diffraction analysis indicates the presence of crystallite in polymers which usually results to improve mechanical properties, unique thermal behavior, and increased fatigue strength. These attributes make crystalline polymers desirable materials for biomedical applications. Also, amorphous components of the hybrid composite would present an improved biodegradation behavior of a biomedical material. It was observed from the morphological analysis that there was good interfacial interaction between the chitosan and the dispersion of the silica reinforcement material. The TA of the sample was carried out to investigate the effect of silica reinforcement on the thermal stability of the hybrid composite. It was discovered that the reinforcement of the silica matrix and its reaction with the polymer makes the thermal resistance of the hybrids to increase and hence, increase in thermal decomposition temperature.
\end{abstract}

Keywords: Polymer; Chitosan; Silica; Hybrid; Reinforcement; Amorphous; Polysaccharide

\section{Introduction}

The utilization of biomaterials in humans has experienced a great success in surgery, dentistry, orthopedics and the likes. For instance, heart valves prostheses are fabricated from carbons, metals, elastomers, fabrics and natural valves and other tissues chemically pretreated to reduce their immunologic response and to enhance durability [1]. Also, the human hip joints are fabricated from titanium, specific high strength alloys, ceramics, composites and ultrahigh molecular weight polyethylene. Dental implants fabricated from titanium materials to form an artificial tooth on which a crown is affixed. One of the advantages of the titanium implants is the bonding with the bone of the jaw. However, this attachment has been more accurately described as a tight apposition of mechanical fit and not true bonding [2]. Wear, corrosion and mechanical properties of titanium have also been of concern [3]. Several other materials have been used to fabricate these implants. Some of these include hydrogel, bioglass, hydroxylapatite, chitosan, and amorphous silica and others (Abere et al, 2017; Abere et al., 2018, Abere et al., 2019). This work attempts to produce a composite of bio glass and chitosan for biomedical application.

Chitosan is a unique polysaccharide produced from chitin (Nam et al, 2010). It has been globally used due to its excellent biocompatibility, low toxicity and biodegradability for diverse biomedical 
applications such as orthopedics, dental implants, drug delivery and others $[4,5]$. The application of chitin in the biomedical field started from the investigation of the reaction and chemical attributes of lysozyme; an enzyme in the human body fluids. It dissolves certain bacteria by cleaving to the chitinous material of the cell walls. It has been suggested that chitosan may be used to inhibit fibroplasias in wound healing and to stimulate tissue growth and differentiation in tissue culture [6].

Silica based biomaterials, such as melt-derived bioactive glasses and sol-gel glasses, have been used for a long time in bone healing applications because of their ability to form hydroxyl apatite and to stimulate stem cell proliferation and differentiation [7]. They have also been reported to support the differentiation of osteoclasts. For these reasons silica based biomaterials have been suggested to be used as bone filling materials or as part of tissue engineering scaffolds in bone repair. Chemically, the most simple silicate material is silicon dioxide, or silica ( $\mathrm{SiO} 2$ ). Structurally, it is a three-dimensional network that is generated when every corner oxygen atom in each tetrahedron is shared by adjacent tetrahedral. Thus, the material is electrically neutral and all atoms have stable electronic structures [3]. Silica fiber like every other fiber possesses a great strength, hence it is envisaged that if blended with chitosan and a hybrid fiber is made of the composite, it will enhance the strength of the material [8].

It has been discovered that most medical problems cannot be corrected by either the natural healing or traditional surgical process [9]. In such cases, implants made from biomaterials can be successfully used to interface with living host tissue to give remedies [10]. Hence, this work attempt to synthesize, characterize and fabricate a hybrid, nanofiber composed of chitosan and bio-silicate glass for biomedical application by preparing an organic and inorganic hybrid cross linking network and electro spinning process to produce the nanofiber.

\section{Materials and Method}

\section{Silica separation from rice husk ash}

Rice husks were obtained from Owode, Ogun state, Nigeria and incinerated at $650{ }^{\circ} \mathrm{C}$ for a period of 4 hours to form rice husk ash. The ash was mixed with the solution of 1 molar concentration of sodium hydroxide $(\mathrm{NaOH})$ solution. The result was sintered at $850^{\circ} \mathrm{C}$ for 3 hours to form sodium silicate (NaSiO3)

\section{Synthesis of chitosan}

The cowry shell was washed thoroughly to get rid of impurities such as sand, dust, dirt and insect larva before sun drying. The subsequent product was pulverized to produce a powder of particle size of 250 microns which was subjected to the following chemical hydrolysis processes to form chitosan $[11,12]$.

Deproteinization: $80 \mathrm{~g}$ of the powder was weighed into a conical flask and $100 \mathrm{ml}$ of $4 \% \mathrm{NaOH}$ was added. $\mathrm{NaOH}$ was prepared by weighing $4 \mathrm{~g}$ of $\mathrm{NaOH}$ pellet and dissolved and made up in $100 \mathrm{ml}$ to obtain $4 \% \mathrm{NaOH}$. The mixture was boiled and stirred at $100{ }^{\circ} \mathrm{C}$ for $2 \mathrm{hrs}$ in a water bath. It was filtered and washed with deionized water. Red litmus paper was used to check if the base was completely washed away. After the washing, the mixture was filtered and the residue was scraped, gently into the Petri dishes, followed by oven drying at $110^{\circ} \mathrm{C}$ for 3 hours. The weight of the sample was $62 \mathrm{~g}$ after deproteinization.

Demineralization: $1 \mathrm{M} \mathrm{HCl}$ was prepared by measuring $55 \mathrm{ml}$ of Conc. $\mathrm{HCl}$ and mixed with 1liter of distilled water in a cylindrical flask of $1000 \mathrm{~cm} 3.5 \%$ of the prepared solution was measured $(30 \mathrm{ml})$ and mixed with the deproteinized sample. The mixture was boiled and stirred for 60 minutes at $100{ }^{\circ} \mathrm{C}$ in a water bath. Subsequent washing was done with distilled water followed by filtration. The mixture was examined with blue litmus to check the acidity of the mixture. The residue (chitin) obtained from above was scarped into the Petri dish and dried in the oven at $100{ }^{\circ} \mathrm{C}$ for $2 \mathrm{hrs}$.

Deacetylation: The isolated chitin was soaked in $510 \mathrm{ml}$ of $50 \%$ $\mathrm{NaOH}$ (weighing $50 \mathrm{~g}$ of $\mathrm{NaOH}$ pellets and dissolved in $100 \mathrm{ml}$ of distilled water), boiled at $100{ }^{\circ} \mathrm{C}$ for $2 \mathrm{hrs}$ in water bath and cooled for 30 mins at room temperature. The mixture was placed on a magnetic stirrer at $30{ }^{\circ} \mathrm{C}$ for $4 \mathrm{hrs}$, filtered, washed and examined with red litmus to check if the base was completely washed away. The mixture was filtered to retain the solid matter which is chitosan. The chitosan was oven dried at $90 \stackrel{\circ}{\circ}$ for $24 \mathrm{hrs}$.

\section{Preparation of Silica-Polymer (chitosan- Polyetheleneoxide) Solutions}

Polymer solutions were prepared with distilled water and glacial acetic acid. The concentration of the polymer solutions was prepared in wt/wt\%.

i. Chitosan-PEO (Polyetheleneoxide) solution with total polymer concentration of $1.6 \%$ were prepared by dissolving chitosan and PEO in 50\% glacial acetic acid in the ratio 3:1, 2:1, $1: 1$.

ii. The polymer solutions were stirred over night to allow homogeneity of the solutions.

iii. Silica solution was prepared by weighing $1.5 \mathrm{~g}$ of the synthesized silica from RHA and dissolved in $25 \mathrm{ml}$ of $1 \mathrm{M} \mathrm{NaOH}$ with continuous stirring at $60{ }^{\circ} \mathrm{C}$ until a clear solution of $\mathrm{Na}-$ SiO3 (bioglass) was obtained.

iv. The polymer solutions and silica concentration were prepared in vol/vol mixing. $10 \mathrm{ml}$ of each of the polymer solution in $3: 1,2: 1,1: 1$, with silica concentration of $0.5 \mathrm{ml}, 1 \mathrm{ml}$ and $1.5 \mathrm{ml}$ mixed together with each of the polymer solution in the given ratio. Table $1 \& 2$

v. The solutions were used immediately for the electrospinning. 


\begin{tabular}{|c|c|c|}
\hline Polymer Solutions in Ratio Chitosan: PEO (wt/wt) \% & Voltage (kv) & Time of Deposition (mins) \\
\hline \multirow{3}{*}{$3: 1$} & $10 \mathrm{kv}$ & \multirow{3}{*}{30} \\
\hline & $15 \mathrm{kv}$ & \\
\hline & $20 \mathrm{kv}$ & \\
\hline \multirow{3}{*}{$2: 1$} & $10 \mathrm{kv}$ & \multirow{3}{*}{30} \\
\hline & $15 \mathrm{kv}$ & \\
\hline & $20 \mathrm{kv}$ & \\
\hline \multirow{3}{*}{ 1:01 } & $10 \mathrm{kv}$ & \multirow{3}{*}{30} \\
\hline & $15 \mathrm{kv}$ & \\
\hline & $20 \mathrm{kv}$ & \\
\hline
\end{tabular}

\begin{tabular}{|c|c|c|c|}
\hline Table 2: Polymer Silica Solution with Electrospinning Parameters. & \multicolumn{2}{|c|}{ Voltage (kv) } & Deposition Time (mins) \\
\hline Polymer Ratio in vol concentration (10m) & Silica Concentration (m) & $10,15,20$ & 30 \\
\hline $3: 1$ & 0.5 & & \\
\hline & 1.0 & 1.5 & $3,15,20$ \\
\hline $1: 1$ & 0.5 & 1.0 & 30 \\
\hline
\end{tabular}

vi. Fiber deposits were collected on $1 \mathrm{~cm} \times 1 \mathrm{~cm}$ glass slides and aluminum foil.

Electrospinning parameters; distance $10 \mathrm{~cm}$ (between the tip of the spinneret and the aluminum collector) and deposition time is 30 minutes for each of the solution. Electrospinning parameters; distance $10 \mathrm{~cm}$ (between the tip of the spinneret and the aluminum collector) and deposition time is 30 minutes for each of the solution.

\section{Electrospinning of the solutions}

The polymer solutions were poured into the spinneret (tilted at $10^{\circ}$ ) with the positive terminal of the voltage source dipped into the polymer solution and the negative terminal attached to the aluminum collector for the fibers. The target was placed $10 \mathrm{~cm}$ from the tip of the spinneret. All operation was carried out at room temperature.

\section{Characterization}

The chemical composition of the rice husk ash produced was investigated through Energy Dispersive X-ray Fluorescence (EDXRF), (MiniPAL4 PANalytical B.V. Lelyweg1 7602 EA, Aimelo). Press powder technique was employed to prepare the sample before the analysis. The physical interactions between chitosan and silica were examined with the aid of Fourier Transform Infrared Spectrometer (FTIR). The samples were scanned at a wavelength of $400 \mathrm{~cm}^{-1}$ to $4000 \mathrm{~cm}^{-1}$. The surface and cross sectional morphology of the sample was investigated with Scanning Electron Microscopy (SEM). The samples were prepared in smaller pieces and sputter with gold before making the observation.

\section{Thermogravimetry Analysis (TG)}

$12 \mathrm{mg}$ of the sample was used to perform the TGA from 50 to $800{ }^{\circ} \mathrm{C}$ with a heating rate of $10{ }^{\circ} \mathrm{C} / \mathrm{min}$ in a dynamic synthetic air atmosphere with the aid of TGA-50 Shimadzu automatic analyzer.

\section{Results and Discussion}

\section{Characterization}

Fourier transform infra-red analysis (FT-IR): FT-IR (Model IR Prestige 21, Shimadzu) analysis was carried out on the extracted samples (chitosan and silica), electrospun nanofiber composites. The results obtained was compared to those of commercial silica and chitosan to identify the presence of hydrogen bond silanol group and the siloxane groups in silica and to evaluate the compositional and chemical features of the extracted chitosan and the nanofiber composite. The results are shown in Figure 1- 5. 

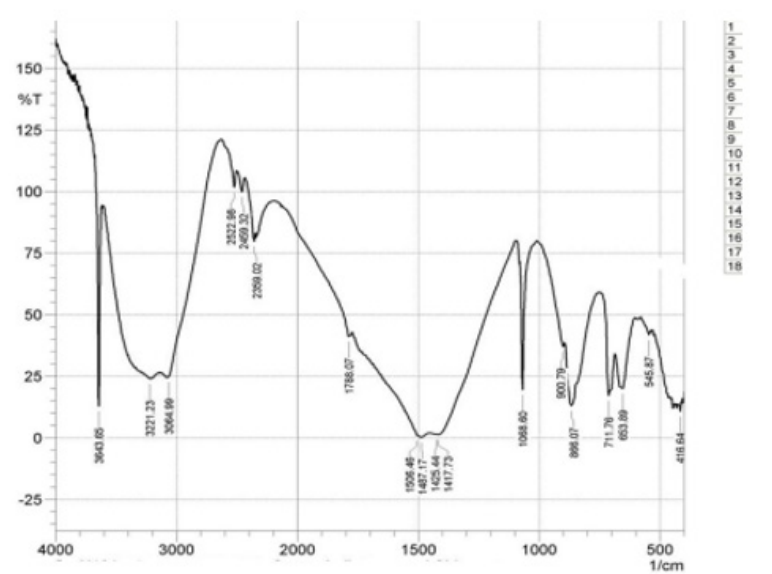

Figure 1: FT-IR pattern for extracted chitosan from cowry shell.

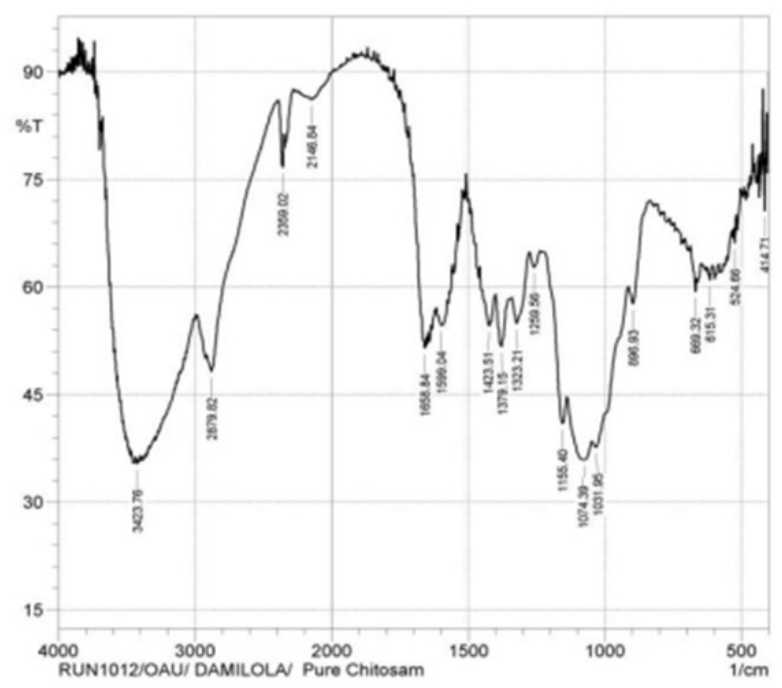

Figure 2: FT-IR pattern for commercial Chitosan.

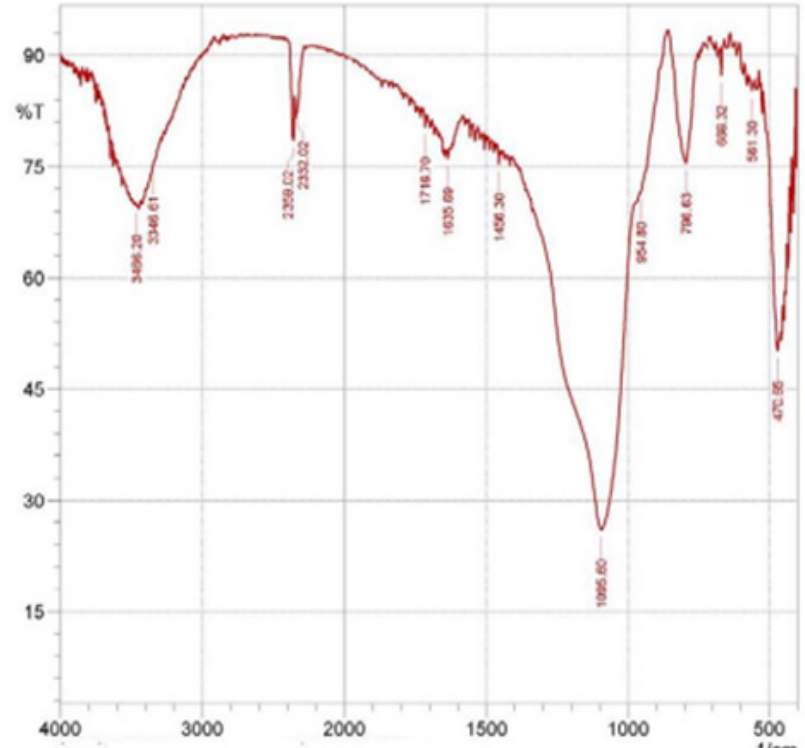

Figure 3: FT-IR pattern of commercial silica. 


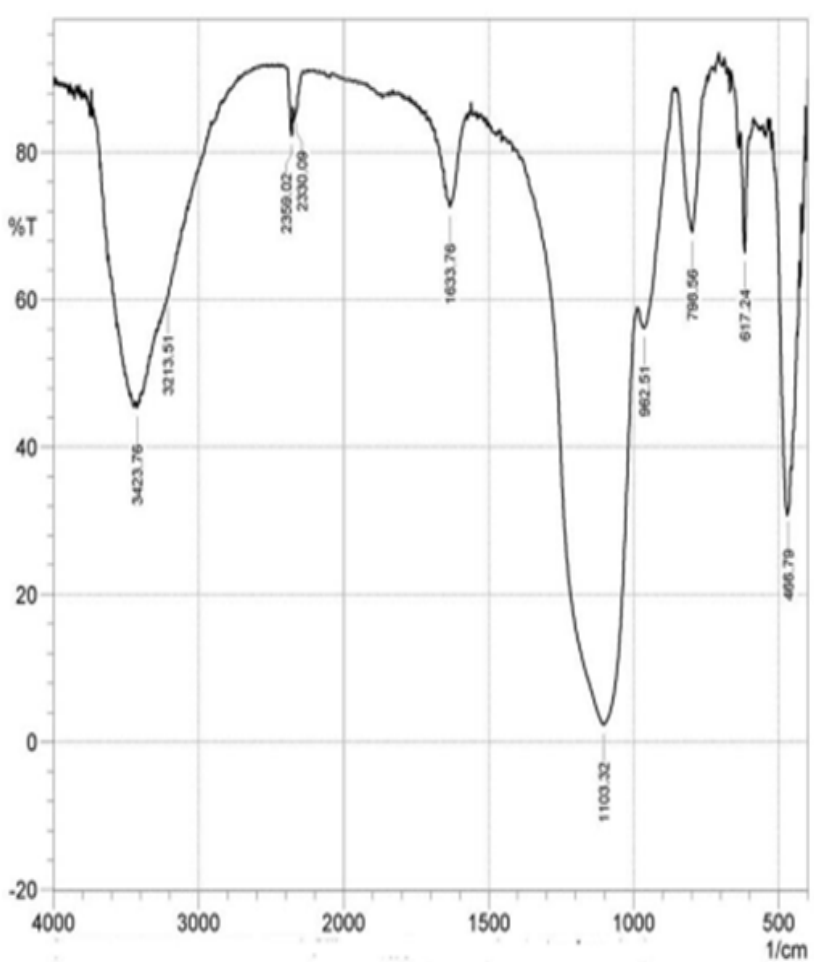

Figure 4: FT-IR pattern for extracted silica from RHA.

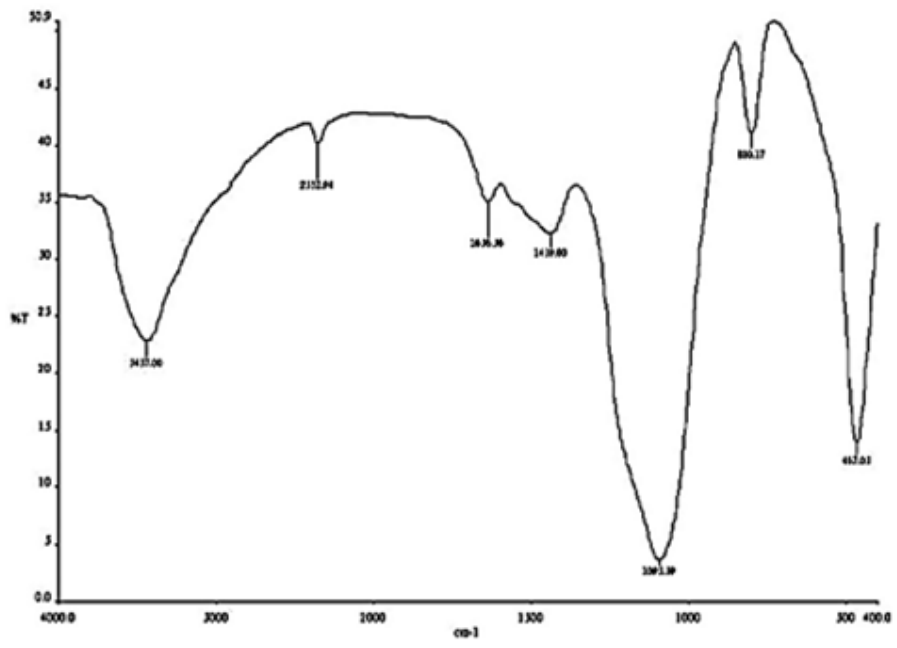

Figure 5: FTIR spectrum of chitosan - silica hybrid

\section{Discussion}

The extracted chitosan (polymer) solution on electropinning did not form fibers; but drops and beads were formed with low degree of fiber deposition even at higher viscosity. This is in agreement with reports from other literatures that showed that electrospinning of chitosan in aqueous solvent was unsuccessful unless another electrospinning-inducing polymer [13] such as PEO is introduced into the solution. On addition of PEO, an increase in polymer viscosity was observed which led to the formation of nanofiber deposited on aluminum foil and glass surface.

\section{ED-XRF analysis}

The product of the incinerated process of rice husk was white rice husk ash whose chemical composition was investigated by ED- XRF analysis (Table 3). It can be observed from Table 3 that the major constituent of rice husk ash is silica (SiO2) which occurs with some other metallic oxides like alumina, ferric oxide, titanium oxide, calcium oxide, magnesium oxide, zinc oxide, manganese (II) oxide, phosphorus pent oxide and others [14]. 
Table 3: ED-XRF Analysis of rice husk.

\begin{tabular}{|c|c|c|c|c|c|c|c|c|c|}
\hline Chemical Composition & $\mathrm{SiO}_{2}$ & $\mathrm{CaO}$ & $\mathrm{Al}_{2} \mathrm{O}_{3}$ & $\mathrm{MgO}$ & $\mathrm{MnO}$ & $\mathrm{K}_{2} \mathrm{O}$ & $\mathrm{Fe}_{2} \mathrm{O}_{3}$ & $\mathrm{P}_{4} \mathrm{O}_{10}$ & Others \\
\hline \% Composition & 88.2 & 1.81 & 0.72 & 0.43 & 0.55 & 5.01 & 0.1 & 0.3 & 2.88 \\
\hline
\end{tabular}

\section{FTIR results analysis}

The characteristic absorption bands for extracted chitosan were observed as follows from Figures 1 \& 2; the peak on the band $3643.65 \mathrm{~cm}^{-1}$ is attributed to the $\mathrm{OH} \cdots \mathrm{O}$ stretching vibration and $\mathrm{N}-\mathrm{H}$ band which lies between $3221.23 \mathrm{~cm}-1$ and $3064.99 \mathrm{~cm}^{-1}$ shows the intermolecular hydrogen bonding of the chitosan polymer molecules [9,15]. The peaks at $2522.98 \mathrm{~cm}^{-1}, 2459.32 \mathrm{~cm}^{-1}$, and 2359.02 can be attributed to the primary amine and - $\mathrm{NH} 2$ secondary amine absorption band respectively (IR correlation chart). Three peaks at $1487.17 \mathrm{~cm}^{-1}, 1425.44 \mathrm{~cm}^{-1}, 1417.73 \mathrm{~cm}^{-1}$ assigned to the deformation of $\mathrm{C}-\mathrm{CH} 3$ band and the band $1506.46 \mathrm{~cm}^{-1}$ may be attributed to the carbonyl C=0-NHR band [9]. At $1068.60 \mathrm{~cm}^{-1}$ is attributed to skeletal vibration involving $\mathrm{C}-\mathrm{O}$ stretching. These peaks confirm the characteristics features for the polysaccharide structure of chitosan [16] extracted from cowry shells.

After the extraction of silica from rice husk ash, the major chemical and functional groups were identified from the FTIR spectra as shown in Figures 3 \& 4. The highest peak observed at wave number $1103.32 \mathrm{~cm}^{-1}$ was due to the siloxane bonds (Si-O-Si) and (Si-O-Si) vibration between $1000 \mathrm{~cm}^{-1}$ and $500 \mathrm{~cm}^{-1}$ band. The peak at wave number $3423.76 \mathrm{~cm}^{-1}$ and $3213.51 \mathrm{~cm}^{-1}$ indicate the presence of silanol $\mathrm{OH}$ functional group. Also, the characteristic and positions of the peaks observed in the extracted silica spectra showed similar position with that of the commercially available silica obtained from BDH chemicals UK as shown by the FTIR spectra results. The silanol group gives the extracted silica a significant potential for application as matrices of many chemical species such as organic molecules, metals and polymeric materials.

The electrospinning of composite solutions may lead to differences in composition of the pre-spun solutions and the deposited fibers [13]. As a result of this the composition of the electrospun fibers was analyzed by FT-IR. From figure 5 the characteristic band in $3650-3180 \mathrm{~cm}^{-1}$ is attributed to the overlapping of $\mathrm{Si}-\mathrm{OH}$ stretch and amine band. Also, the spectral bands in $2110-2400 \mathrm{~cm}^{-1}$ are as a result of $\mathrm{Si}-\mathrm{H}$ stretch which overlaps $\mathrm{C} O$ vibration. There was an $\mathrm{AC}$ at $\mathrm{O}$ band at $1636 \mathrm{~cm}^{-1}$ [17]. The adsorption peak at $1442 \mathrm{~cm}^{-1}$ is similar to in-plane $\mathrm{OH}$ bending. The peak observed at $1075 \mathrm{~cm}^{-1}$ is related to Si AO ASi stretch [17] whereas the peak at $780 \mathrm{~cm}^{-1}$ is associated to the overlapping of Si AC stretch and NH2wag. The peak at $459 \mathrm{~cm}^{-1}$ is assigned to $\mathrm{O}-\mathrm{Si}$ - bending [18]. The large intensity of the peak at $1080 \mathrm{~cm}^{-1}$ might be due to the overlapping of the Si AO ASi and the AC AO AC A of glycosidic linkage $[17,19]$. Chitosan-silica hybrid has $\mathrm{Si} \mathrm{AOH}$ and $\mathrm{Si} \mathrm{AO} A S i$ with the respective bands within the regions of $3270-3400 \mathrm{~cm}^{-1}$ and $989-1300 \mathrm{~cm}^{-1}$ [16].

\section{XRD results analysis}

The diffraction pattern from amorphous materials (including many polymers) is devoid of the sharp peaks characteristic of crystals and consists of broad features or halos. The X-ray diffraction pattern of chitosan twelve peaks were identified at $2 \theta$ with the peaks showing an hydrated partially crystalline material with amorphous background identified between $55^{\circ}$ to $70^{\circ}$ at $2 \theta$. This result suggests that the extracted chitosan is a semi crystalline polymeric material.

The XRD spectra of $20^{\circ}$ diffraction between $30^{\circ}$ and $40^{\circ}$ showed three specific peaks at $31.27^{\circ}, 32.98^{\circ}$ and $37.89^{\circ}$. These features of extracted silica spectrum suggested the characteristic of amorphous micro porousilica [18]. The XRD result is presented in Figure 6. From the pattern, on comparison with known standards in the JCPDS Powder Diffraction File for silica (Joint Committee on Powder Diffraction Standards) Figure 7. Amorphous components would present an improved biodegradation behavior of a material [3]. The presence of crystallite in polymers usually leads to enhanced mechanical properties, unique thermal behavior, and increased fatigue strength. These properties make semi crystalline polymers (often referred to simply as crystalline polymers) desirable materials for biomedical applications [3].

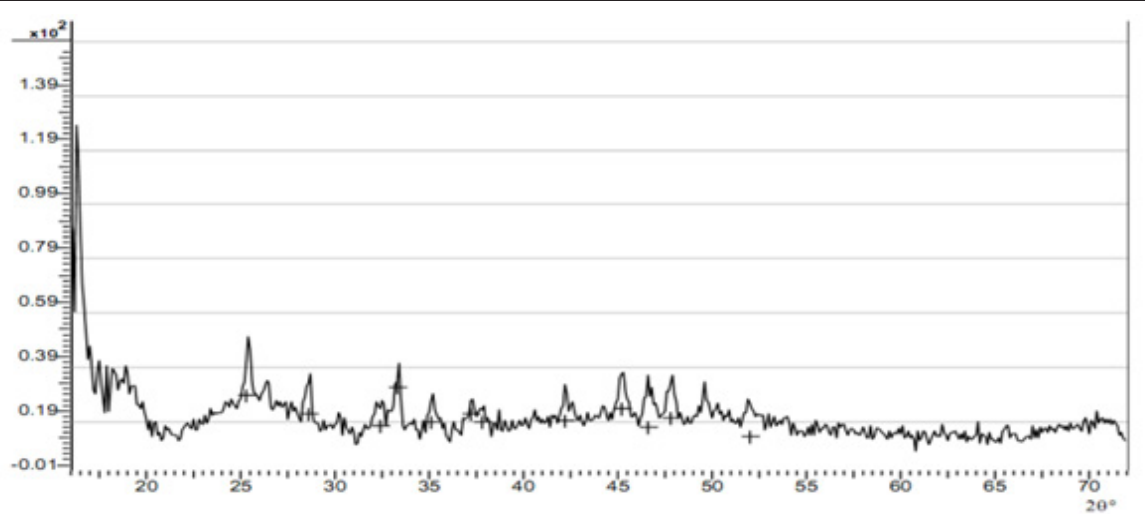

Figure 6: XRD analysis spectrum for extracted chitosan. 


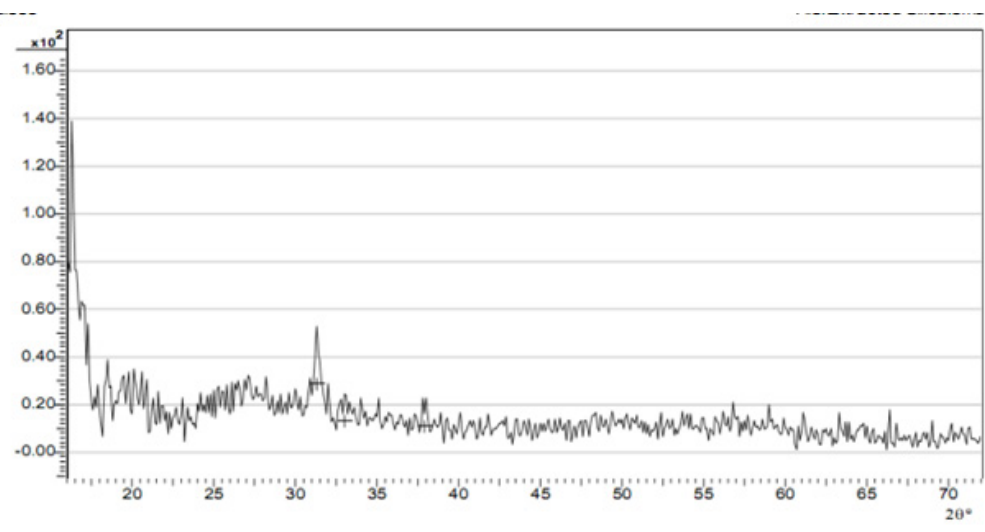

Figure 7: XRD spectrum analyses for extracted Silica.

The XRD analysis of chitosan -silica hybrid was also carried out to examine the crystal phase, orientation and their structural properties. It can be observed from Figure 8, that the peak of the most crucial amorphous curve is at 23.3 in the $2 \mathrm{~h}$ angle that reveals the state of the amorphous of the silica network while chitosan occur in the anhydrous crystalline form. It had been stated that the anhydrous crystalline chitosan and amorphous silica is at $2 \mathrm{~h}=23$ while a highly discrete crystalline projection found at $2 \mathrm{~h}$ angle of 29.3 reveals the impact of the silica form $[20,21]$.

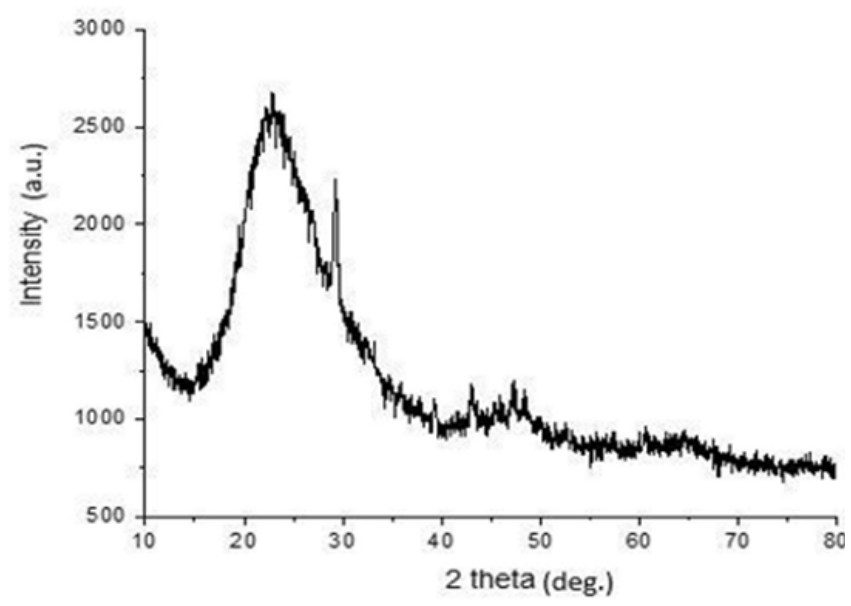

Figure 8 : XRD spectrum pattern of chitosan-silica hybrid

\section{SEM analysis}

The particles of silica in the composite occur in the form of white round beads, and their dispersion within the matrix is clearly visible as in Figure 9. The homogeneous and dense structure of silica in the matrix of chitosan can be observed in the hybrid composite as the concentrations of $\mathrm{SiO} 2$ increases. This indicates good interfacial interaction within the chitosan and the dispersion of the silica reinforcement material. The bright spots indicate the silicon element clearly reflect a uniform distribution of silica in Chitosan-Silica hybrid domains. The nanometer rate of dispersion of silica in chitosan shows the influence on the thermal properties of the hybrid.

Thermogravimetic Analysis

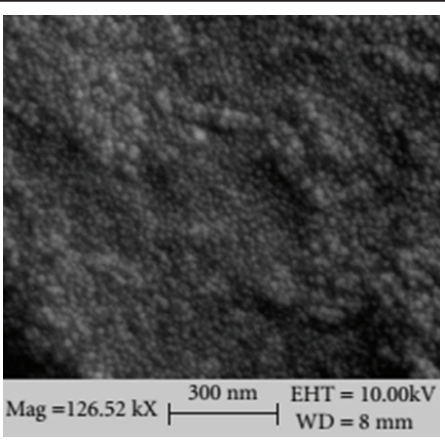

Figure 9 : SEM micrographs of Chitosan-Silica nanocomposite 
Thermogravimetric analysis of the chitosan silica nano-composites was performed in synthetic air within the range of 50-750 ${ }^{\circ} \mathrm{C}$ to investigate the influence of silica reinforcement on the thermal stability of the hybrid composite. It could be observed from Figure 10 that the weight loss which could be observed within 105 and $170{ }^{\circ} \mathrm{C}$ might be as a result of the loss of moisture content present in chitosan and subsequent product of condensation of the $\mathrm{Si}-\mathrm{OH}$ groups [22]. Chitosan has low rate of weight loss in the axis ranging between $175^{\circ} \mathrm{C}$ and $290{ }^{\circ} \mathrm{C}$ because of the decomposition of low molecular weight species [22]. The rate of thermal decomposition is much around $180{ }^{\circ} \mathrm{C}$ and $465^{\circ} \mathrm{C}$ due to the complex dehydration of the saccharide rings, depolymerization, and decomposition of the acetylated and deacetylated units of the polymer [23]. Therefore, the incorporation of silica and its reaction with the polymer makes the thermal resistance of the hybrids to increase and hence, increase in thermal decomposition temperature [24,25].

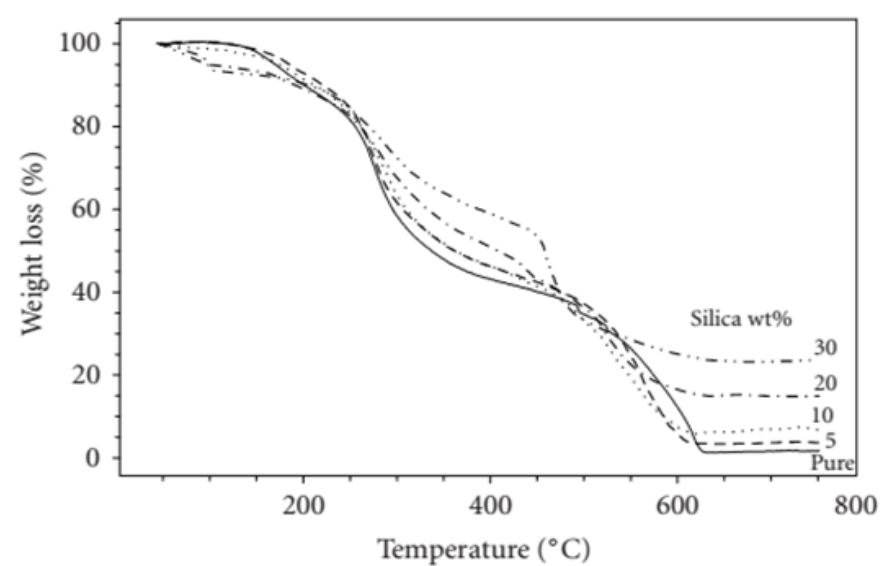

Figure 10: thermogravimetric curves for the Chitosan-Silica nanocomposite

\section{Conclusion}

Silica was obtained through the incinerated process of rice husk and subjected to chemical analysis to examine the chemical composition of the rice husk ash while chitosan was synthesized through chemical hydrolysis process from cowry shell. The products obtained from the incinerated and hydrolysis processes were made into fiber through electrospinning technique. The hybrid composite formed was subjected to various characterization techniques. It was observed that the major constituent of rice husk ash is silica (SiO2) with some associate metallic oxides. The crystalline nature of polymers will improve mechanical properties, unique thermal behavior, and increase fatigue strength. These attributes make crystalline polymers desirable materials for biomedical applications. Whereas, the amorphous component of the hybrid composite would present an improved biodegradation behavior of a biomedical material. It was observed from the morphological analysis that there was good interfacial interaction between the chitosan matrix and the dispersion of the silica reinforcement material.

\section{References}

1. Park SB, You JO, Park HY, Haam SJ, Kim WS (2001) Biomaterials, Park $\left(22^{\text {nd }}\right.$ edn), France.

2. Anderson DG, Burdick JA, Langer R (2004) Smart Biomaterials Science. 305: 1923-1924.

3. Ratner BD, Hoffman AS, Schoen FJ, Lemons JE (2004) Osteoconduction at Porous Hydroxyapatite with Various Pore Configurations. Biomaterials, Volume 21(12): 1291-1298.

4. Abere DV, Oyatogun GM, Akinwole IE, Abioye AA, Rominiyi AL, et al (2017) Effects of Increasing Chitosan Nanofibre Volume Fraction on the Mechanical Property of Hydroxyapatite. American Journal of Materials Science and Engineering 5(1): 6-16.

5. Akinwole IE, Alebiowu G, Oyatogun GM, Abere DV, Adenigba AE, et al. (2018) Synthesis and Characterization of Cowry and Crab Shells Based Chitosan for Drug Delivery. Bioceram Dev Appl 8: 107.

6. Betre H, Setton LA, Meyer DE, Chilkoti (2002) A Characterization of a genetically engineered elastin-like polypeptide for cartilaginous tissue repair. Biomacromolecules 3: 910-916.

7. Chang B, Lee C, Hong K, Youn H, Ryu H, et al. (2000) Osteoconduction at Porous Hydroxyapatite with Various Pore Configurations. Biomaterials 21(12): 1291-1298.

8. Langer R., Tirrell DA (2004) Designing materials for biology and medicine. Nature 428: 487- 492.

9. Raif EM, Harmand MF (1993) Molecular interface characterization in human bone matrix: Biochemical and IR Spectroscopic Studies. Biomaterials 14: 978-984.

10. Meinel L, Holfman S, Karageorgion V, Zichnew L (2004) Engineering cartilage-like tissue using human mesenchymal stem cells and silk protein scaffolds. Biotechnological engineering 88(3): 379-391.

11. Nam YS, Won HO, Park Daewoo I, Samuel M, Hudson (2010) Effect of the degree of deacetylation on the thermal decomposition of chitin and chitosan nanofibres. Carbohydrate Polymers 80: 291-295.

12. Luo XL, Xu JJ, Wang JL, Chen HY (2005) Chitosan composite. Chem Commun 21: 69-72.

13. Li Z, Yubao L, Aiping Y, Xuelin P, Xuejiang W, et al. (2005) Preparation and in vitro investigation of chitosan/nano-hydroxyapatite composite used as bone substitute materials. J Mater Sci Mater Med 16: 213-219.

14. Battegazzore D, Bocchini S, Alongi J, Frache A (2014) Rice Husk as Biosource of Silica: Preparation and Characterization of PLA-Silica Biocomposites. RSC Adv 4: 54703-54712.

15. Li H, C Zhou, M Zhu, J Tian, J Rong (2010) Preparation and Characterization of Homogeneous Hydroxyapatite/Chitos a 
Composite Scaffolds via In-Situ Hydration. Journal of Biomaterials and Nanobiotechnology 1(1): 42-49.

16. Al-Sagheer F, Muslim S (2010) Thermal and mechanical properties of chitosan/SiO2 hybrid composites. J Nanomater 1-7.

17. Prerna D, Ramanand J (2012) Comparative study of physical and thermal properties of Chitosan - Silica hybrid coatings prepared by solgel method. Pelagia Reseach Library Der Chemica Sinica 3(3): 589-601.

18. Azadeh T, Marzieh H, Vahid M, Masoud R (2013) Synthesis and characterization of hydrophobic silica aerogel by two step (acid-base) sol-gel process. JNS 3: 181-189.

19. Yeh JT, Chen CL, Huang KS (2007) Synthesis and Properties of Chitosan/ $\mathrm{SiO}_{2}$ Hybrid Materials. Mater Lett 61: 1292-1295.

20. Todorova EV, Chernev GE, Djambazov SP (2014) Structure and properties of functionalized porous silica hybrid materials. Open J Inorg Non-Metal Mater 4: 35-43.

21. Kow, Kien Who, Yusoff, Rozita, Abdul Aziz, et al. (2014) From bamboo leaf to aerogel: Preparation of water glass as a precursor J Non-Cryst Solids 386: 76-84.
22. Budnyak TM, Tertykh VA, Yanovska ES, Kolodyńska D, Bartyzel A (2015) Adsorption of V(V), Mo (VI) and Cr (VI) Oxoanions by Chitosan-silica Composite Synthesized by Mannich Reaction. Adsorption Sci Tech 33: 645-657.

23. Mahatmanti FW, Nuryono AO, Narsito BG (2016) Adsorption of Ca (II), Mg (II), Zn (II) and Cd (II) On Chitosan Membrane Blended with Rice Hull Ash Silica and Polyethylene Glycol. Indones J Chem 16: 45-52.

24. Abere DV, Oyatogun GM, Oluwasegun KM, Ojo SA, Akinwole IE, et al. (2019) Development and Characterization of Cowry Shell Based Hydroxyapatite for Dental and Orthopaedic Applications. Arch Biomed Eng \& Biotechnol 2(4): 2019.

25. Abere DV, Oyatogun GM, Oluwasegun KM, Ayodele TJ, Ajayi SV, et al. (2018) Synthesis and Characterization of Alumina-ChitosanHydroxyapatite Bio composites for Load Bearing Application. European Scientific Journal (ESJ) 14(30): 145-165. 